\title{
Del servicio militar obligatorio a la voluntariedad ${ }^{1}$
}

\author{
From mandatory military service to voluntary service
}

Jamás nadie organizó una república o un reino sin advertir que los mismos que los habitaban tenian que salvaguardarlos con las armas.

Maquiavelo

Daniel José Vásquez Hincapié2 Román Francisco Téllez Navarro ${ }^{3}$

Recepción: 8 de agosto de 2016 Aprobación: 20 de enero de 2017

\section{Resumen}

El presente artículo evidencia la necesidad de operar el tránsito de un servicio militar obligatorio a uno voluntario y profesional, en consonancia con la nueva forma de Estado instaurada a partir de la Constitución de 1991, cuyo fundamento es el respeto de la dignidad de la persona humana. Muestra cómo existen al respecto países que ya han realizado esta transición evidenciando que en los Estados modernos es innecesario el servicio militar obligatorio, ya que con la abolición de este no se menoscaba la defensa de su seguridad, mientras que con la

1 Artículo producto del estado del arte del proyecto de investigación Del tránsito del servicio militar obligatorio a la voluntariedad. Dicho proyecto fue gestionado fue gestionado en la Universidad Militar Nueva Granada de Bogota

2 Doctor en Derecho, Universidad CEU San Pablo; Magíster en Derecho Administrativo, Universidad Sergio Arboleda; Especialista en Derecho Administrativo; Abogado, Universidad la Gran Colombia; Profesional en Ciencias Militares, y docente del área de Derecho Público de la Universidad Militar Nueva Granada. Correo electrónico: daniel.vasquez@unimilitar.edu.co

3 Magíster en Derecho Procesal Penal, Universidad Militar Nueva Granada; Especialista en Derecho Constitucional y Abogado, Universidad Libre de Colombia y docente del área de Derecho Público de la Universidad Militar Nueva Granada. Correo electrónico: Correo electrónico: roman.tellez@unimilitar.edu.co 
profesionalización de dicho servicio, las labores de defensa y seguridad son más efectivas. El artículo refiere una fórmula con la cual puede solventarse la defensa y la seguridad del Estado colombiano a partir de las reservas activas, las cuales, en caso de guerra, suplirían la ausencia de los contingentes integrados por jóvenes obligados a prestar el servicio militar. Finalmente, se presenta un análisis de los pronunciamientos de la Corte Constitucional frente a la exequibilidad de la norma que establece el servicio militar como obligatorio, así como el primer asomo de la terminación de esta imposición a partir de la objeción de conciencia y la ausencia del legislador para regular esta voluntariedad, pese a la recomendación de dicha Corte.

Palabras clave: servicio militar obligatorio, objeción de conciencia, Estado social de derecho.

\begin{abstract}
This paper highlights a need to make a transition from a compulsory military service to voluntary-and-professional enlistment in line with the new way of state established by Constitution in 1991, whose cornerstone is the constitutional value and principle as a function of basic right of dignity of the human being. Faced with this view there are some countries having done this transition, evidencing that modern states don't require the compulsory military service since its abolition is not a detriment to security; otherwise, a professionalization of this job could result in a more effective defense and security. This paper also addresses a formula that could solve the defense and security issues of the Colombian state thanks to active military reserve members that, in the event of war, would supply the lack of youth forced. Finally, an analysis of the Constitutional Court rulings against the enforceability of this standard as well as ending this obligation from a conscientious objection and a legislature absence to rule this voluntarism despite the recommendation by the Constitutional Court.
\end{abstract}

Keywords: compulsory military service, conscientious objection, Social Rule of Law.

\title{
INTRODUCCIÓN
}

La prestación del servicio militar ha sufrido cambios drásticos en los últimos cuarenta años, desde cuando Inglaterra decidió cambiar el servicio militar obligatorio por el servicio profesional. Hoy siguen siendo dos las causas para que los Estados cambien 
su forma de conscripción: la primera es la búsqueda de eficiencia militar mediante la profesionalización del soldado y, la segunda, el rechazo de la juventud ante el proceso de selección del soldado que usualmente se realiza de manera inequitativa. Al respecto, es preciso recordar que "uno de los aspectos de la iusfilosofía es su historia trimilenaria; tratar de comprender esa historia es algo siempre luminoso para entender sus momentos y para proyectar el porvenir" (Duran, 2016, p. 15).

En Colombia también se aceptan como válidas estas críticas, aunque la experiencia siga demostrando que tal obligación es inequitativa y que a la guerra siguen llegando solo los más necesitados, los desprotegidos, quienes poseen menos recursos, aquellos que nada tienen para defender, pero que cargan con la responsabilidad de defender todo lo de los demás.

Se podría decir entonces, que el servicio militar obligatorio no es un asunto contemplado para las élites ni para sus descendientes, pero sí para el resto de la ciudadanía. En concordancia con lo dispuesto en párrafos anteriores, y a modo de contexto de lo que se quiere plantear en las presentes páginas, se considera procedente afirmar que al hablar de poder político, una parte importante de la literatura coincide en su especial relación con el uso de la fuerza y/o violencia organizada (Burgos \& Blanco, 2016, p. 19).

\section{NOTAS SOBRE EL SERVICIO MILITAR EN EL MUNDO ${ }^{4}$}

En Colombia, la obligación de prestar el servicio militar está reservada y definida para los varones, cuando las necesidades públicas encaminadas a la defensa de la independencia y las instituciones así lo exijan. Dicha obligatoriedad está descrita en el artículo 14 de la Ley 48 de 1993, así: "Todo varón colombiano tiene la obligación de inscribirse para definir su situación militar dentro del lapso del año anterior en que cumpla la mayoría de edad", a lo que se agrega, además, que dicha obligación termina el día en que cumplan los cincuenta (50) años de edad y que, parágrafo del artículo 10, "La mujer colombiana prestará el servicio militar voluntario, y será obligatorio cuando las circunstancias del país lo exijan y el Gobierno nacional lo

4 En el presente desarrollo se abordará el tema de manera general y no se abarcarán todos los países. 
determine, en tareas de apoyo logístico, administrativo, social, cultural o de defensa de la ecología y el medio ambiente".

Por otra parte, existen modalidades de prestación del servicio militar obligatorio, es decir, que este servicio puede prestarse como soldado regular, bachiller, auxiliar de policía bachiller y soldado campesino, clasificación que define el tiempo de duración del mismo, el cual oscila entre los doce (12) y los veinticuatro (24) meses.

Para iniciar la prestación del servicio existe la necesidad de una instrucción previa, así como dedicación y ubicación diferenciada, más parecida a una diferenciación por clases sociales que a una obligación universal para sus asociados, de acuerdo con sus competencias, divergencia que vuelve a hacerse palpable al contemplarse la exención de los limitados físicos e indígenas durante todo tiempo y otras más durante los tiempos de paz.

Si bien la Ley 48 de 1993 en los artículos 11 y 13 determina las modalidades y los tiempos de la prestación de servicios dependiendo de su cualificación, ya sea como soldado regular, soldado bachiller, auxiliar de policía bachiller y como soldado campesino y la obligación de tomar las armas para defender la independencia y las instituciones públicas, esta norma únicamente determina las actividades a desarrollar por los soldados bachilleres, extensivas a los auxiliares de policía bachilleres, así: "Los soldados, en especial los bachilleres, además de su formación militar, y demás obligaciones inherentes a su calidad de soldado, deberán ser instruidos y dedicados a la realización de actividades de bienestar social a la comunidad y en especial a tareas para la preservación del medio ambiente y conservación ecológica” (Parágrafo del artículo 13).

Por otra parte, y de conformidad con el artículo 13, los soldados campesinos prestarán su servicio militar obligatorio en la zona geográfica donde residen. Así, es evidente la inequidad en la prestación del servicio, puesto que al determinar que los bachilleres realizarán, en especial, tareas administrativas y ecológicas, la ley los excluye de tareas operacionales de combate, las cuales se hacen exclusivas para los soldados regulares y los campesinos, relegando a estos de la posibilidad de realizar tareas con la comunidad y de conservación del medios ambiente.

En Argentina, el servicio militar tuvo obligatoriedad desde comienzos del siglo XX hasta que en 1994, mediante decreto del Poder Ejecutivo Nacional, luego convali- 
dado por la ley, suspendió el servicio militar obligatorio remplazándolo por un sistema de tropas voluntarias y profesionalizadas. Así lo sostienen Lafferriere y Soprano (2014, p. 17) al señalar que "El sistema de conscripción previsto por esa ley estuvo vigente hasta su suspensión en 1994 y la sanción de la Ley 24.429 de servicio militar voluntario que implicó la profesionalización del conjunto del personal de las Fuerzas Armadas”.

En rigor, la ley anterior no fue derogada; solo se dejó sin efecto sine die la convocatoria a conscriptos, quedando abierta la posibilidad de reclutamiento obligatorio para un eventual caso de emergencia. En el nuevo esquema, solo quienes deseen enrolarse en las fuerzas armadas (FF. AA.) y tengan entre 18 y 26 años de edad, sean varones o mujeres, formarán parte del Ejército, la Armada o la Fuerza Aérea.

En Chile, la nueva modalidad de servicio militar, vigente desde abril de 2006, propende por satisfacer los requerimientos anuales de soldados conscriptos de las fuerzas armadas, inicialmente con jóvenes voluntarios, voluntariedad en principio, y de no lograrse esto, establece que se completen los cupos faltantes con jóvenes no voluntarios, obligatoriedad en subsidio, seleccionados a través de un proceso de sorteo bajo condiciones de justicia, transparencia y debidamente comunicado.

El nuevo sistema de reclutamiento dejó sin efecto la obligación que tenían los jóvenes de concurrir a inscribirse para el servicio militar. En remplazo de tal obligación, dispone la aplicación de un sistema de inscripción automática en los registros militares una vez cumplen los 18 ańos de edad, mediante la transferencia de datos que realiza el Registro Civil e Identificación a la Dirección General de Movilización Nacional; esta última debe publicar y difundir anualmente, en abril, la respectiva base de conscripción para el año, conformada por los integrantes del citado Registro Militar y por los jóvenes disponibles del año anterior.

Como lo dispone la Dirección General de la Movilización Chilena, el sistema senalado persigue y promueve completar las cuotas de acuartelamiento de soldados conscriptos requeridos por las FF. AA., inicialmente solo con jóvenes voluntarios que deben concurrir personalmente para manifestar su consentimiento al cantón de reclutamiento correspondiente a su domicilio. De no alcanzar las cuotas de contingente requeridas por las fuerzas armadas con los voluntarios, se efectuará un sorteo 
general, con los no voluntarios, en forma proporcional por comunas, para determinar quiénes de los que integran la referida base de conscripción serán convocados adicionalmente para cumplir con el servicio militar.

En Venezuela, de acuerdo con las políticas de la nueva forma de Estado (denominado República Bolivariana) y la Ley de Conscripción y Alistamiento Militar de 2009, el servicio militar es obligatorio para hombres y mujeres debiéndose cumplir en forma regular en las fuerzas armadas nacionales, así como sometiéndose a la instrucción militar de acuerdo con las normas establecidas o que se establezcan en las leyes y reglamentos. Para esta norma, la edad de prestación del servicio es denominada edad militar, que es el periodo durante el cual los venezolanos y venezolanas tienen obligaciones militares, y está comprendida entre 18 y 60 años.

En México, según las políticas de registro y obtención de la Cartilla del Servicio Militar Nacional (SMN), la obligación de prestar el servicio militar nacional comprende exclusivamente a los varones mexicanos por nacimiento, así como por naturalización. Esta obligación comienza cuando cumplen los 18 años de edad, con el registro inicial y finalmente con la obtención de la cartilla del servicio militar nacional, documento que expide la Secretaría de la Defensa Nacional a todo mexicano que cumple con dicho servicio, ya sea en México o en el extranjero. La obligación termina el 31 de diciembre del año en que los varones mexicanos cumplen 40 años de edad.

En Israel, al igual que en Venezuela, es obligatorio que todos los hombres y mujeres, al cumplir 18 años, presten servicio militar. Los hombres realizan un servicio militar por un periodo de tres años y las mujeres un servicio de 21 meses; ambos con la posibilidad de ser contratados, si es que el Ejército los requiere, por un periodo de unos años o de por vida. Solo una vez terminado el servicio militar, pueden empezar la universidad.

España, de acuerdo con lo dispuesto en el Real Decreto 247/2001 de 9 de marzo, a partir del 31 de diciembre de 2001, suspendió la prestación del servicio militar obligatorio, siguiendo la tendencia de Francia, Bélgica, Gran Bretaña, Luxemburgo, Japón, Australia, Estados Unidos y Canadá, de no tener servicio militar obligatorio. Sin embargo, la obligatoriedad de este servicio se mantiene en Dinamarca, Grecia, Noruega, Austria, Finlandia, Irlanda, Suecia, Rusia y China, entre otros. Alemania, 
Italia y Portugal, entre otros, adoptaron otra política manteniendo un servicio militar de tinte mixto, en que menos del $10 \%$ de los enlistados corresponde al servicio obligatorio.

\section{El SERVICIO MILITAR Y EL EsTado SOCIAL DE DERECHO}

La concepción del Estado social de derecho colombiano impone especial cuidado en la relación que debe tener el Estado, el ordenamiento jurídico y los asociados, bajo la premisa del constitucionalismo contemporáneo, que funda su actuar en la teoría jurídica de los límites del poder y que ha colocado la dignidad de la persona humana como su centro y objetivo de servicio, razón por la cual el texto constitucional hace manifiesto que los fines del Estado son:

Servir a la comunidad, promover la prosperidad general y garantizar la efectividad de los principios, derechos y deberes consagrados en la Constitución; facilitar la participación de todos en las decisiones que los afectan y en la vida económica, política, administrativa y cultural de la nación; defender la independencia nacional, mantener la integridad territorial y asegurar la convivencia pacífica y la vigencia de un orden justo (Const., 1991, art. 2. ${ }^{\circ}$ ).

Concepto que de plano impulsa a distinguir las atribuciones del otrora Estado social, donde la relación del pueblo era una de subordinación que imponía servir, proteger y engrandecer al Estado, propia de las soberanías nacionales, y no al pueblo en las formas de los Estados sociales de derecho como el colombiano.

En todo caso, la obligación de prestar el servicio militar en Colombia se fundamenta en el enunciado normativo de que "Todos los colombianos están obligados a tomar las armas cuando las necesidades públicas lo exijan, para defender la independencia nacional y las instituciones públicas, con las prerrogativas y las exenciones que establece la presente ley” (Ley 48 de 1993, art. 3).

Bajo esta premisa, podría considerarse que el Estado tiene el derecho de garantizar su propia seguridad y que, por lo tanto, las personas tienen la obligación de prestarlo; lo que debe establecerse es cómo pueden las personas cumplir tal obligación dentro 
de un Estado social de derecho como el colombiano, en el cual la autonomía y las objeciones de conciencia tienen estrecha relación con la dignidad humana.

Resultaría inaceptable que actualmente se manifieste que no hay alternativas y que por ser una obligación legal, el servicio militar deba cumplirse sin más explicaciones, bajo el concepto de que la legitimidad de la limitación de los derechos está condicionada por criterios de razonabilidad y proporcionalidad, puestos de manifiesto en la obligación ceñida al criterio de una norma de orden público.

El Estado colombiano, bajo la nueva concepción de Estado, se encuentra al servicio de la comunidad y posee como valores superiores la dignidad humana y la prevalencia de los derechos de las personas, tal como emana de los artículo 1, 2 y 5 de la Constitución Política, por lo que la imposición de obligaciones debe ser compatible con el respeto a ellos, de tal forma que si la Constitución Política declara que, el derecho a la vida es inviolable, corresponde entonces a las autoridades proteger y garantizar la seguridad de las personas y no que las personas sean obligadas a proteger y ser garantes de la seguridad del Estado, manifiesto que la Corte Constitucional argumenta señalando que "los deberes exigibles a las personas no pueden hacerse tan rigurosos que comprometan el núcleo esencial de sus derechos fundamentales" (Sentencia C-251 del 11 de abril de 2002), como lo es la vida misma.

Así las cosas, es evidente que el servicio militar no debe ser obligatorio y que el Estado deberá procurar los medios que mejor considere para la defensa de su propia institucionalidad y soberanía, así como la supervivencia, en condiciones dignas de los asociados, bajo la perspectiva y la consecución del individuo como ciudadano y no como súbdito.

Lo dispuesto anteriormente ha de comprenderse con los mismos cambios que el concepto de nación ha evidenciado. Para el efecto, es importante hacer referencia a la profesora Carreño (2016, p.13) para quien dicho concepto ha estado presente en los desarrollos del pensamiento constitucional colombiano. Noción que aunque de reciente incorporación en la reflexión de la filosofía política, es de gran importancia para determinar la forma como se piensa, se comprende y se proyecta el hoy denominado Estado constitucional. 


\section{EL PRECEDENTE CONSTITUCIONAL Y EL SERVICIO MILITAR en Colombia}

Cuando el Estado colombiano, mediante la Ley 40 de 1993, prohibió el pago de rescates para liberar secuestrados, la Corte Constitucional, en Sentencia C-542 de 1993, encontró que tal prohibición vulneraba la Carta, entre otras razones, porque desconocía los derechos fundamentales, pues no era lícito exigir de un ser humano el sacrificio de la vida y de la libertad, propias o ajenas, aduciendo la primacía del interés general sobre el individual, postura ratificada por el salvamento de voto de la misma sentencia resaltando la primacía de la autonomía de la persona cuando señaló que "Los derechos a la vida y a la libertad no pueden sacrificarse por la persona en aras del interés general, salvo cuando la propia persona acepta el sacrificio voluntaria y libremente" (Salvamento de voto, Sentencia C-542 del 24 de noviembre de 1993).

Está claro que, en defensa del interés general, la mencionada ley quiso regular el pago de rescates y nada más que esto. Sin embargo, el fallo de la Corte va más allá porque tiene fundamento en la defensa de la vida, que se constituye, precisamente, en el hecho creador de conexidad para producir la integración del derecho referido con la prestación obligatoria del servicio militar.

En la sentencia por la cual declaró la inexequibilidad de la Ley 684 de 2001, Ley de Seguridad y Defensa Nacional, la propia Corte Constitucional ha dejado claro que, en materia de servicio militar obligatorio, también hay límites, al señalar:

Si el riesgo para la vida o la integridad no resulta imperioso o necesario, considerada la situación concreta, no ha de propiciarse su exigencia. El deber de arriesgar la vida no es absoluto. En relación con los deberes, únicamente pueden ser exigibles en su integridad cuando el obligado a ellos está en capacidad efectiva de cumplirlos, pues, al igual que los derechos, también tienen sus límites. Deben existir diferentes niveles en los cuales se puede cumplir con la obligación constitucional de tomar las armas teniendo en cuenta el entrenamiento, disposición y aptitudes de quien va a defender la independencia, soberanía e integridad institucional. Quienes prestan el servicio militar obligatorio en su condición de bachilleres o campesinos, si bien están obligados a tomar las armas y reciben para ello una formación mínima, si su preparación 
y adiestramiento en el aspecto militar y de defensa personal no alcanza niveles evidentes de proporcionalidad frente al peligro que afrontan, por razón del corto tiempo de servicio o la configuración física del conscripto menor de edad, por ejemplo, no es admisible que se asigne justamente a los menos preparados la responsabilidad más grave, o una igual o equivalente a la del soldado cuya formación en esos campos es más completa. Por ello, las tareas más peligrosas y la responsabilidad de ataque y respuesta armada en zonas y situaciones calificadas como de alto riesgo deben ser atendidas en primer lugar por los soldados voluntarios, luego por los regulares y solo en última instancia por los bachilleres y campesinos (Sentencia C-251 de 2002).

El argumento de interpretación dado por la Corte a una norma con la que se procuró la defensa del principio de primacía del interés general sobre el particular, se aplica entonces en su totalidad a la obligación de prestar el servicio militar obligatorio pues tiene cimiento en el principio de inviolabilidad del derecho a la vida, porque se prescriben iguales en la identidad de su razón, que es la protección de la vida humana, una obligación primordial radicada en el Estado.

La prestación del servicio militar no implica por sí un riesgo para la vida en los países que se encuentran en paz, pero sí lo es en aquellos como Colombia, donde se vive un estado de conflicto interno permanente, con características similares a los de una guerra. El servicio militar obligatorio, como precepto constitucional impuesto a los ciudadanos no puede sobreponerse al derecho a la vida, aunque sea norma de derecho público que corresponde al imperio de la ley, ya que el Estado ha excedido sus atribuciones frente al soberano, es decir, el pueblo, porque este no le ha otorgado la capacidad de disponer de su vida, ni siquiera de ponerla en riesgo. Las personas pagan sus impuestos para que el Estado tenga los medios que le permitan cumplir con sus fines, entre los cuales está el ser responsable de dar seguridad a las personas y no al contrario.

Dicha consideración no se asimila a la conformación de un pueblo indolente ante los riesgos, porque cuando la propia vida y la libertad están amenazadas, los ciudadanos voluntariamente accederán a la prestación del servicio militar como reacción natural de su propia condición humana, hecho demostrado en que la adopción del servicio militar profesional y voluntario en varios países europeos y americanos no ha colo- 
cado en indefensión ni ha generado riesgos en la seguridad de ninguno de ellos. El problema de mantener la lealtad y el amor patriótico hacia el Estado no se define por la lengua, las costumbres, la raza o la historia común, sino por la presencia de una Constitución y unas normas que permitan al Estado garantizar la libertad y el bienestar de sus ciudadanos, y de un gobierno que demuestre la capacidad de realizarlas, protegerlas y garantizarlas.

En la integración del derecho antes expuesto, es superior la razón de la defensa de la vida de quienes son obligados a prestar el servicio militar obligatorio, porque a diferencia del caso de los secuestrados, estos pueden defender la vida con su dinero mediante el pago del rescate, mientras el soldado, generalmente, asume el servicio por carecer de él, porque el servicio militar en Colombia es inequitativo, siendo únicamente los ciudadanos de escasos recursos los obligados a entregar su vida por los demás, sin más opciones que las de eludir el servicio o esperar que sus propias deficiencias físicas le permitan evitarlo. Desde el punto de vista político, el Estado no ha creado condiciones para que los ciudadanos convivan en paz y el servicio militar es un estado latente de riesgo para la vida de los soldados; y desde el punto de vista jurídico, tampoco el Estado ha logrado que el servicio militar se preste igualitariamente por todos sus ciudadanos, y sigue siendo un servicio militar obligatorio para las clases menos favorecidas.

Así ha empezado a entenderlo el Estado y tras una situación de confrontación que parece tener carácter endémico, se han dado pasos para corregir la misma, por demás injusta, que solo afecta a los más pobres. Actualmente, de acuerdo con el Ejército Nacional, no se recluta a menores de edad y el pie de fuerza está cerca de 250.000 soldados entre los que se incluyen por lo menos 80.000 profesionales, con lo cual se da respuesta parcial al planteamiento inicial de esta sección: la población paga impuestos al Estado, entre otros propósitos, para su seguridad y este contrata a quienes voluntariamente están dispuestos al posible sacrificio de sus vidas en el servicio militar, porque no siendo una obligación exigida y cumplida de manera igualitaria por todos, a nadie puede exigírsele el derecho a la seguridad a expensas de los otros. Es decir, el servicio militar obligatorio debe ser absolutamente abolido conciliando el Estado y los ciudadanos la forma de respetar los derechos que a cada uno le corresponden sin detrimento para ninguno. 
Ante los anteriores planteamientos, la pregunta de quienes nunca prestaron el servicio militar ni están dispuestos a que sus hijos lo hagan es entonces: ¿Qué vamos a hacer cuando sea declarada la guerra? ¿Quiénes se encargarán de nuestra defensa? La respuesta es dada por la misma Corte Constitucional en repetidas sentencias en las que recomienda al Estado abolir el servicio militar obligatorio, y entonces el servicio militar podría ser ya totalmente profesional. Para tal efecto, solo se requiere que soldados profesionales asuman el control de medios e instalaciones, dejando a los soldados reclutados como reservas en funciones de entrenamiento y participación en la atención de calamidades públicas, control de eventos electorales y para las necesidades de la guerra de acuerdo con la decisión soberana del pueblo. En este mismo sentido, se resuelve la inquietud de quienes refutan la solución aduciendo consideraciones económicas, cuando manifiestan que el país no está en la capacidad de asumir tal carga administrativa, pues en nada varían las condiciones salariales y el gasto de funcionamiento que se tiene en el presente.

En la actualidad, la Dirección de Reclutamiento y Movilización del Ejército Colombiano, al expedir la tarjeta de reservista a quienes terminan la prestación del servicio militar obligatorio y a los que definen su situación, los enlista en las unidades militares de la especialidad cercanas a su lugar de origen o donde estará radicado, para que conozcan la guarnición a la que pertenecen en caso de ser convocados por decreto de movilización.

Esas unidades no deberían quedarse en el papel ni en la estadística, sino conformar una reserva pasiva de primera línea por un periodo de hasta diez (10) años, con presentaciones periódicas para actualización, lo que las colocaría como reserva de empleo inmediato con ciudadanos no mayores de 35 años. Después de tal periodo en la reserva de primera línea, se pasaría a una reserva pasiva de segunda línea hasta la edad de cincuenta (50) años tal como está configurada en la actualidad. De esta manera, no habría la desprotección y el abandono de la defensa del Estado que alegan algunos.

Por otra parte y reforzando los anteriores argumentos, el Concejo de Estado en concepto emitido el 25 de febrero de 2009 , señaló que:

[...] por el rompimiento del equilibrio de igualdad frente a las cargas públicas que se genera al ser incorporado un soldado regular, no todos los ciudadanos es- 
tán llamados a soportar tal situación, y por las mayores contingencias a las que están sometidos en relación con los demás miembros de la sociedad, sufren desmedro físico o fallecen por razón del servicio, los soldados que prestan servicio militar obligatorio no pueden ser destinados a las tareas de combate (Concepto Consejo de Estado, Radicación N. ${ }^{\circ}$ 18001-23-31-000-1995-05743-01(15793).

Este concepto está acorde con nuestra apreciación acerca del servicio militar y, de paso, reduce a la más mínima expresión la competencia de la justicia penal militar, haciéndola también innecesaria durante los tiempos de paz.

\section{SERVicio Militar Y COMUNIDADES INDÍGENAS}

La Ley 48 de 1993, en el artículo 27, determinó que están exentos de prestar el servicio militar obligatorio en todo tiempo "los indígenas que residan en su territorio y conserven su integridad cultural, social y económica"; la calidad de indígena se acreditará con la constancia expedida por el jefe del resguardo o gobernador indígena respectivo, de conformidad con el artículo 26 del Decreto 2048 de 1996.

Se debe entender, entonces, que la protección de los indígenas se hace en reconocimiento de la pluralidad y la naturaleza humana con relación a la diversidad étnica y cultural y de su condición de minoría que representa el $2 \%$ de la población nacional, con 84 pueblos y 61 idiomas, de acuerdo con lo indicado por la Organización Nacional Indígena de Colombia (ONIC). Para hacer efectiva esa protección, el Estado les concede derechos de colectividad con la finalidad de conservar su identidad y lograr la supervivencia como comunidad. Sin embargo, consideraba el Estado que cuando voluntariamente el indígena abandonaba su territorio y su comunidad, como elemento del Estado colombiano donde gozaba de todos los derechos que pertenecer a la misma le otorgaría, estaba también expuesto a cumplir con los deberes imponibles a todos los demás, razón por la cual se incorporaban al servicio militar a los que se hallaban fuera de sus resguardos, como si el sentido de pertenencia estuviese supeditado a la estadía física dentro de la comunidad.

La exclusión del servicio militar para los indígenas residentes en su territorio ancestral en unión con sus colectividades, tuvo especial consideración por la pureza 
cultural y su diferente percepción del mundo de acuerdo con su cosmovisión, usos y costumbres, pero para la exclusión de la prestación del servicio militar los incluía cuando abandonaban su territorio, porque se suponía que la interacción individual y personal con la sociedad, y su integración en ella, le habrían de capacitar para comprender la diferenciación de las normas, la identificación de lo lícito y lo ilícito, la aceptación de las autoridades y de las obligaciones que son generales para todos.

Además de ello, el Ministerio de Defensa Nacional (2003) dictó políticas de protección a las comunidades indígenas, manifestando que la incorporación de indígenas al programa de soldados campesinos debía tener firma voluntaria y no podía hacerse mediante redadas o jornadas especiales de definición de situación militar. De igual manera, en comunicación presentada ante la Corte Constitucional en representación del Ejército Nacional respecto de la Sentencia de Tutela T-113 de 2009, la Dirección de Reclutamiento aceptó que "Sin embargo, se han analizado casos concretos de solicitudes de desacuartelamiento de indígenas que a pesar de no residir en su territorio, conservan su identidad cultural, accediendo a ello" en clara contradicción con las normas institucionales de entonces, hecho que debilitó efectivamente el presunto ejercicio de autoridad y dio argumentos para reclamaciones, exigiendo cada vez mayores prerrogativas con referencia al reclutamiento de indígenas.

Tal circunstancia ocurrió mediante Acción de Cumplimiento, cuyo actor fue el senador Efrén Félix Tarapués Cuaical, que el Tribunal Administrativo de Cundinamarca falló a favor del Ejército Nacional en el caso de la exigencia de desacuartelamiento de indígenas incorporados por decisión voluntaria de cada uno, conceptuando que si bien es cierto que la excepción para la comunidad indígena es una prerrogativa, ella puede ser revocada individualmente.

El Tribunal no hizo mención alguna a que la exigencia del senador de desacuartelar a los indígenas que prestaban sus servicios como soldados campesinos en sus territorios, desconocía las funciones constitucionales de las autoridades indígenas de “[...] vii) colaborar con el mantenimiento del orden público dentro de su territorio de acuerdo con las instituciones y disposiciones del Gobierno Nacional" (Sentencia T-601 de 2011). 
Esta norma de excepción a la prestación del servicio militar por parte de los indígenas fue reformada por la Corte Constitucional mediante sentencia de tutela con base en los siguientes fundamentos:

(i) que el derecho colectivo fundamental a la identidad cultural indígena es una garantía, de la comunidad y de cada uno de sus miembros, para poder actuar según su cosmovisión, dentro y fuera del territorio tradicional; (ii) que el orden constitucional vigente contempla la excepción por diversidad etnocultural en diversos ámbitos, entre ellos, respecto del servicio militar obligatorio; (iii) que la demostración de la condición indígena debe darse a partir de la identidad cultural real de la persona indígena; (iv) que las comunidades indígenas tienen el derecho constitucional de participar en las decisiones que las afecten; $y(v)$ que un joven indígena tiene el derecho a incorporarse al Ejército Nacional a prestar servicio militar 'voluntario' y, por lo tanto, a desincorporarse cuando voluntariamente así lo decida; el consentimiento que el joven indígena otorgue, debe ser libre e informado (Sentencia T-601 de 2011).

El fundamento principal de la decisión corresponde al concepto de que los valores culturales y sociales del indígena pueden expresarse y autodeterminarse dentro y fuera de su territorio, para lo cual manifestó que concluir que la identidad cultural solo pueda expresarse en un lugar determinado o único equivale a establecer políticas de segregación y separación, inaceptables en el Estado colombiano.

Pero de igual importancia, aunque en relación negativa con la correspondencia a la disciplina y la organización militar, es el fundamento que manifiesta el derecho del indígena a incorporarse y retirarse voluntariamente del servicio, que lesiona gravemente la función de prestación del servicio de defensa por parte de la organización militar, aspecto que permite establecer que aún los servidores públicos no saben identificar la condición del soldado en la estructura del Estado.

Tal como se expresa popularmente sobre la incorporación de los soldados al servicio militar, para engrosar las filas de las fuerzas armadas, es una simple incorporación así entendida, por lo ciudadanos y hasta por los funcionarios públicos, sin comprender que el soldado también es un servidor público, que ocupa un puesto en la organización de la defensa nacional, con unas funciones establecidas en los reglamentos y que 
cuya ausencia o abandono produce consecuencias graves para el cumplimiento de la misión militar.

Vale decir, para mejor comprensión, que el soldado indígena puede ser el ametrallador de la primera escuadra, del primer pelotón, de la compañía A, de un batallón de infantería, de la brigada $Y$, perteneciente a la división $Z$ del Ejército Nacional, si quisiese voluntariamente retirarse, no sería posible aceptar su manifestación, porque no existe como en la función pública, la opción de nombramiento de su reemplazo cuando se produzca la vacante, pero sí podría colocar su unidad en una disminución de su capacidad operacional, que en un momento determinado puede ser de tal importancia que pueda hacer diferencia entre la vida y la muerte de sus propios compañeros o la de los ciudadanos a los cuales debe proteger. Es decir que el retiro voluntario también tendría unos condicionamiento especiales, entre otros, que no se encuentre desarrollando operaciones militares.

La sentencia citada señaló finalmente que no importa el lugar de residencia, la condición de indígena se mantiene y puede ser invocada no solo por la persona sino por su comunidad, con lo cual el reclutamiento de indígenas solo puede realizarse cuando voluntariamente así lo desee la persona y se lo permitan las autoridades de su comunidad.

\section{La OBJECIÓN DE CONCIENCIA}

Con la nueva Constitución colombiana, adquiere relevancia la dignidad humana, entendida esta como aquellos atributos inherentes a la persona que le permite tomar sus propias decisiones sin que estén limitadas por el Estado, pero con la limitante en los derechos de los demás. Implica lo anterior que el concepto de dignidad dota al ciudadano de un poder que le permite abstenerse de realizar lo que él no considere correcto, siempre y cuando no vulnere un derecho superior, y, en este orden de ideas, la objeción de conciencia tiene un realce sobre todo a la hora de tomar las decisiones que lo afecten de manera individual. De acuerdo con el profesor Muñoz Priego (2010, p. 2), la objeción de conciencia debe entenderse como "la actitud de quien se niega a obedecer una orden de la autoridad o un mandato legal invocando la 
existencia, en su fuero interno, de una contradicción entre el deber moral y el deber jurídico, a causa de una norma que le impide asumir el comportamiento prescrito”.

Pero alegar la objeción de conciencia no puede ser caprichoso ni subjetivo; debe estar y, como lo señala el citado autor, "puede basarse la objeción en particulares convicciones filosóficas, religiosas, morales, humanitarias o políticas y venir referida a conductas de muy variada naturaleza: la guerra, la violencia, el juramento, el servicio militar" (Muñoz, 2010, p. 2).

Frente a la objeción de conciencia y particularmente frente a la prestación del servicio militar obligatorio, la Corte Constitucional, en sentencia de control concreto, ha señalado que "La objeción de conciencia al servicio militar obligatorio es un derecho fundamental y una causal de exención a la prestación de dicho servicio, que tienen raigambre constitucional y, por ende, supra legal" (Sentencia T-455 de 2014).

Amén de lo anterior, la corporación no solo se queda en la dogmática, sino que impone cargas en cabeza de las autoridades militares así:

Para la Corte resulta imperativo que ante esas circunstancias, las autoridades militares pongan en efectivo conocimiento de los ciudadanos obligados (i) el contenido de las causales de exención y aplazamiento del servicio militar obligatorio, entre ellas la objeción de conciencia; y (ii) el procedimiento aplicable para que las autoridades de incorporación y reclutamiento estudien y resuelvan dichas solicitudes, en caso que el ciudadano obligado considere que cumple con las condiciones previstas para ello. Además, con el fin de que esta información sea oportuna, deberá realizarse en el acto de inscripción al servicio y en cualquier caso de forma previa al reclutamiento. Su puesta en conocimiento, de la misma manera, deberá hacerse por un mecanismo efectivo y eficaz, en atención de las condiciones de los conscriptos. Adicionalmente, la Sala resalta que este deber de información se enmarca en obligaciones legales precisas, predicables de todas las autoridades administrativas, entre ellas las encargadas de la incorporación y reclutamiento (Sentencia T-455 de 2014).

Dicha categorización de derecho fundamental también cuenta con un soporte de orden internacional ya que la Declaración Universal de Derechos Humanos dispone 
en el artículo 18 que "Toda persona tiene derecho a la libertad de pensamiento, de conciencia y de religión; este derecho incluye la libertad de cambiar de religión o de creencia, así como la libertad de manifestar su religión o su creencia, individual y colectivamente, tanto en público como en privado, por la enseñanza, la práctica, el culto y la observancia".

Esta teoría no solo se ocupa de las cuestiones previas, sino que también, como se señala en el Informe analítico sobre la objeción de conciencia al servicio militar, emitido por el Alto Comisionado de las Naciones Unidas para los DD. HH. (2013, p. 10), puede invocarse cuando se es incorporado. Dicho informe advierte que "La Comisión de Derechos Humanos indicó en su resolución 1993/84 que era 'consciente de que las personas que están cumpliendo el servicio militar pueden transformarse en objetores de conciencia' y afirmó 'que a las personas que están cumpliendo el servicio militar obligatorio no se les debería negar el derecho a tener objeciones de conciencia al servicio militar'”.

Es evidente que se amplía el espectro de la objeción de conciencia, acogiendo la hipótesis basada en que las personas pueden cambiar de ideología, cultura, religión e ideales políticos y que por ello no pueden ser menguados sus derechos.

De igual manera, "objeción" es un juicio o raciocinio que una persona opone a una idea o propuesta para negarla o impedir su realización o su presentación. Entonces "objeción de conciencia" es un razonamiento moral o religioso para oponerse a realizar una acción. Vale decir que se trata entonces de una autentica expresión de la libertad de conciencia, tal y como lo consagra la Constitución Política colombiana en el artículo 18: "Se garantiza la libertad de conciencia. Nadie será molestado por razón de sus convicciones o creencias ni compelido a revelarlas ni obligado a actuar contra su conciencia”.

No obstante lo anterior, el panorama en Colombia sobre el derecho a objetar conciencia no ha sido constante ni único. El máximo intérprete de la Constitución seńaló en varias jurisprudencias que la objeción de conciencia no era un excluyente de la prestación del servicio militar obligatorio. Postura que cambió con la Sentencia C-728 de 2009, pues como lo señala la Defensoría del Pueblo (2014, p. 102): 
En esta sentencia, la Corte se apartó del precedente constitucional existente sobre la objeción de conciencia y estableció un conjunto de subreglas respecto del ejercicio de este derecho: (1) Definió la objeción de conciencia como una situación individual que obedece al fuero interno de la persona y que supone la presencia de una discrepancia entre la norma jurídica y alguna norma moral. (2) Estableció que la objeción de conciencia frente a la prestación del servicio militar sí se desprende de la protección de los derechos a la libertad de conciencia y a la libertad de cultos. (3) Supeditó la posibilidad de presentar una objeción de conciencia a la valoración que en cada caso concreto se realice en torno a los elementos que configuran la reserva de conciencia y a la naturaleza del deber que da lugar al reparo. (4) Resaltó que si a la luz de ese análisis se concluye que hay lugar para la objeción de conciencia, la falta de previsión legislativa sobre el particular no puede tenerse como un obstáculo para la efectividad del derecho, el cual podría ejercerse directamente con base en la Constitución. (5) Fijó a todo objetor de conciencia la obligación de probar que su conciencia ha condicionado y determinado su actuar de tal forma que prestar el servicio militar obligatorio implicaría actuar en contra de ella, así como que sus convicciones o creencias (que pueden ser de carácter religioso, ético, moral o filosófico) son profundas 109 , fijas110, sinceras 111 y susceptibles de ser alegadas.

A pesar de los diferentes pronunciamientos de orden internacional y nacional aunado a las tendencias de abolir el servicio militar obligatorio, el Congreso de la República de Colombia ha sido renuente a reglamentar dos aspectos fundamentales del mismo. El primero corresponde a la profesionalización del servicio y con ello a abolir la obligatoriedad del mismo, y, el segundo, a legislar sobre el derecho fundamental a la objeción de conciencia, quedando como herramienta para el ciudadano objetor el control constitucional abstracto para que le sea reconocido dicho derecho fundamental.

Amén de lo anterior, el senador Eugenio Prieto (2012), presentó proyecto de ley sobre la objeción de conciencia en que señaló:

La Constitución Política fundamenta la objeción de conciencia en los artículos 1, respeto de la dignidad humana y pluralismo; 7, diversidad étnica y cultural; 
13, derecho a la no discriminación, principio de igualdad; 16, cláusula general de libertad; 18, libertad de conciencia y 19, libertad de religión y cultos, de acuerdo con la Convención Americana de Derechos Humanos, en cuyo artículo 12 se consagra la libertad de conciencia y de religión; el Pacto Internacional de Derechos Civiles y Políticos y la Declaración sobre la eliminación de todas las formas de intolerancia y discriminación fundadas en la religión o en las convicciones, proclamada por la Asamblea General de las Naciones Unidas en 1981.

Para Dieterlen (2002, p.71), según la ética kantiana, "lo ideal sería que la Constitución otorgara mayor libertad humana sin afectar la libertad de otros, así la objeción de conciencia debería ser considerada después de verificar si su aplicación aumenta la libertad de todos o simplemente la del objetor o si la libertad del objetor significa un deterioro para la libertad de los demás”.

Según los defensores de la objeción debe considerarse esta como un logro no determinado solamente para quienes están dispuestos a ejercerla, sino inclusive para para todos los demás ciudadanos, y, en contraposición, habría de considerarse que la libertad de acción dada al objetor significa un deterioro en el cumplimiento de las obligaciones por parte de quienes aceptan cumplirlas, aunque lo hagan voluntariamente.

Respecto del servicio militar obligatorio, la objeción de conciencia en precisa observación jurídica tiene objetivos políticos que, no obstante, no pueden calificarse como tendenciosos en búsqueda de la desprotección del Estado, pues con ella algunas organizaciones religiosas buscan dar cumplimiento a sus objetivos de paz para sus asociados, mientras otras de carácter político tratan de disminuir la disponibilidad de personas involucradas en el ejercicio de las actividades armadas.

Lo anterior tiene sustento en la propia Constitución Política en cuyo Título II se contemplan los derechos (art. 11 a 41) y, por lo tanto, no requeriría que se regule la objeción de conciencia al servicio militar pues la sola libertad de conciencia expresada dentro de los límites y alcances dados en los tratados internacionales de Derechos Humanos hacen suficiente la argumentación para defenderla. Así lo reconoce la Corte Constitucional cuando manifiesta que: 
En ese orden de ideas, se generan dos deberes constitucionales específicos para las autoridades militares. En primer lugar, están llamadas a reconocer y evaluar a la objeción de conciencia como una de las causales jurídicamente vinculantes para la exención del servicio militar obligatorio. Para ello, no podrán en ningún caso invocar la inexistencia de una previsión legal o reglamentaria que así lo establezca, puesto que la objeción de conciencia es un derecho de índole constitucional y, por esa razón, obligatorio para todas las personas y autoridades, en los términos del artículo 4 C.P. (Sentencia T-455 del 7 de julio de 2014).

Contemplada entonces la objeción de conciencia como un derecho constitucional que determina otra exención a la prestación del servicio militar, nos encontramos ante la obligación de una modificación a la normatividad del servicio militar y ante otro argumento para replantear su obligatoriedad.

\section{Otras normas QUE AFECTAN La Obligatoriedad DEL SERVICIO MILITAR}

El Ministerio del Trabajo impulsó la Ley 1780 del 2 de mayo de 2016, mediante la cual se realizan modificaciones reglamentarias al servicio militar que afectan gravemente su obligatoriedad:

Artículo 19. Reducción de la edad máxima de incorporación a filas para la prestación del servicio militar. Los colombianos declarados aptos por el Ministerio de Defensa Nacional para prestar el servicio militar podrán ser incorporados a partir de la mayoría de edad hasta faltando un día para cumplir los veinticuatro (24) años de edad. Artículo 20. Acreditación de la situación militar para el trabajo. La situación militar se deberá acreditar para ejercer cargos públicos, trabajar en el sector privado y celebrar contratos de prestación de servicios como persona natural con cualquier entidad de derecho público. Sin perjuicio de la obligación anterior, las entidades públicas o privadas no podrán exigir al ciudadano la presentación de la tarjeta militar para ingresar a un empleo. Las personas declaradas no aptas, exentas o que hayan superado la 
edad máxima de incorporación a filas podrán acceder a un empleo sin haber definido su situación militar.

Las decisiones de la Corte Constitucional también han incidido en la forma en que los ciudadanos asumen su obligación de prestar el servicio militar obligatorio mandada por la Constitución Política: "A este respecto, la Corte debe ser enfática en indicar que las autoridades militares no tienen competencia para hacer redadas o batidas indiscriminadas, con el propósito de identificar a quienes no han resuelto la situación militar, para conducirlos a instalaciones militares e proceder a incorporarlos" (Sentencia T-455 de 07 de julio de 2014).

En el ejercicio de su función de reclutamiento, las autoridades militares solo tienen entonces la facultad de solicitar el documento de identificación al ciudadano para inscribirlo, sin que ello implique en esa primera instancia la posibilidad de retenerlo para resolver su situación militar, cosa que solo podrá ejecutarse una vez el ciudadano ha sido previamente examinado y declarado apto para su prestación y este se rehúse, con lo cual se le declara remiso y a partir de tal circunstancia, está en posibilidad de ser compelido a cumplir con la obligación. Si no es obligatorio presentarse a definir la situación militar y las autoridades solo pueden inscribir al ciudadano por suerte del azar para que sea imperiosa su presentación, el servicio no es en realidad obligatoria sino opcional.

\section{Conclusiones}

En sus orígenes, los ejércitos fueron creados para mantener una idea, una postura o una ideología, y eran el mando y la subordinación sus principales herramientas doctrinales, por lo cual los regímenes absolutistas se soportaban en ellos para mantenerse en el poder. Sin la ayuda y el apoyo de un ejército, su poder era nulo. Para mantener lo anterior, era necesario que el servicio militar fuera obligatorio y prolongado en el tiempo, bajo remuneraciones atractivas y bajo castigos severos para aquellos que se atrevieran a resistirse a cumplir la obligación.

Dentro del actual desarrollo de las políticas de defensa de las grandes potencias y de algunos países de Suramérica, ha quedado abolido el servicio militar obligatorio y 
cambiado por el servicio militar voluntario con un énfasis en la profesionalización del mismo y encaminando su actuar más a labores de índole social y comunitaria, reservando las actividades de defensa y combate solo si es necesario. No obstante lo anterior, es pertinente precisar que aunque el servicio militar se determine voluntario, la obligatoriedad de prepararse para la defensa debe ser conservada por el Estado.

Aunque en Colombia el servicio militar continúa siendo obligatorio, es necesario señalar que bajo la condición del Estado social de derecho, este debe ser voluntario y profesional, pues se cuentan con los recursos necesarios y, adicionalmente, como quedó demostrado, en ningún momento quedará desprotegido el Estado frente a una posible amenaza a su defensa.

Adicional a lo anterior, y de mantenerse la postura del servicio militar obligatorio, el Estado seguiría desconociendo que las excepciones, salvo las relacionadas con la condición física de la persona, convierten el servicio militar en una obligación relativa que puede y viene siendo desconocida por los ciudadanos. De igual manera, de mantenerse esta postura, se estaría contrariando el espíritu de la Constitución, en la cual es el Estado quien defiende al ciudadano y no lo contrario.

Si bien es cierto que existe un mandato de la Corte Constitucional para legislar sobre la posibilidad de objetar conciencia, para omitir la prestación del servicio militar obligatorio, esto no resuelve de fondo el asunto, pues no solo se trata de no cumplir, sino que los principios y valores del actual forma de Estado, Estado social de derecho, donde prima la persona sobre cualquier organismo del Estado, el servicio militar deber ser voluntario.

Finalmente y teniendo en cuenta las recomendaciones de los organismos internacionales, en las cuales conmina al Estado colombiano a que regule la transición del servicio militar obligatorio por uno voluntario bajo la figura de profesionalización del soldado, Colombia tiene una deuda con la sociedad ya que después de más de quince años de recomendaciones de la Corte Constitucional por la adopción del servicio militar voluntario, no hay decisión asertiva del Estado, convirtiéndose en otra asignatura pendiente. 


\section{REFERENCIAS}

Alto Comisionado de las Naciones Unidas para los DD. HH. (2013). Informe analitico sobre la objeción de conciencia al servicio militar. Recuperado de: http://www.acnur.org/t3/ fileadmin/Documentos/BDL/2014/9457.pdf?view=1

Burgos, Germán \& Blanco, Carolina (2016). "El monopolio de la violencia estatal" en Estado, Constitución y Territorialidad, pp. 19-49. Bogotá: Editorial Universidad Libre.

Carreño, Dalia (2016). El concepto de nación en las constituciones políticas colombianas del siglo XIX al siglo XX, en Historiografía, persona y nación, pp. 13-47. Bogotá: Editorial Ibáńez. Recuperado de: http://porticus.usantotomas.edu.co/bitstream/11634/1481/1/ Historiografia $\% 2 c \% 20$ persona $\% 20 y \% 20$ nacion.pdf

Colombia, Congreso de la República. Ley 48 de 1993, por la cual se reglamenta el servicio de reclutamiento y movilización.

Colombia, Congreso de la República. Ley 1780 del 2 de mayo de 2016, por la cual se promueve el empleo y el emprendimiento juvenil, se generan medidas para superar barreras de acceso al mercado de trabajo y se dictan otras disposiciones.

Colombia, Corte Constitucional. Sentencia C-251 de 2002. MM. PP. Eduardo Montealegre Lynett y Clara Inés Vargas Hernández.

Colombia, Corte Constitucional. Sentencia C-542 del 24 de noviembre de 1993, salvamento de voto.

Colombia, Corte Constitucional. Sentencia T-113 de 2009. M.P. Clara Elena Ruales Gutiérrez.

Colombia, Corte Constitucional. Sentencia T-601 de 2011. M.P. Jorge Iván Palacio.

Colombia, Corte Constitucional. Sentencia T-455 de 2014. M.P. Luis Ernesto Vargas Silva.

Colombia, Consejo de Estado. Radicación N.o 18001-23-31-000-1995-05743-01(15793). Concepto del 25 de febrero de 2009.

Colombia, Defensoría del Pueblo (2014). Servicio militar obligatorio en Colombia: Incorporación, reclutamiento y objeción de conciencia. Defensoría Delegada para los Asuntos Constitucionales y Legales. 
Colombia. Ministerio de Defensa Nacional. Circular N. ${ }^{\circ} 264$ de 2003. Politicas ministeriales a las comunidades indígenas.

Colombia, Presidencia de la República. Decreto 2048 de 1993, Por el cual se reglamenta la Ley 48 de 1993 sobre el servicio de reclutamiento y movilización.

Constitución política de Colombia (1991). 2.․ Bogotá: Editorial Legis.

Dieterlen Struck, Paulette (2002). "La objeción de conciencia”, en Revista CODHEM, p. 71. Recuperado de: www.revista-colaboración.jurídicas.unam.mx

Duran, Juan Guillermo (2016). Iusfilosofia con ventanas. Bogotá: Editorial Ibáńez. Recuperado de: http://porticus.usantotomas.edu.co/bitstream/11634/1479/1/Iusfilosofia\%20 con\%20ventanas.pdf

Lafferiere, G \& Soprano, G. (2014). "El servicio militar voluntario en las fuerzas armadas argentinas entre el final del siglo XX y principios XXI”. Revista Conjuntura Austral. Vol. 5, N. ${ }^{\circ}, 24$ jun-jul.

Muñoz Priego, Blas Jesús (2010). La objeción de conciencia. Recuperado de: http://www.bioeticacs.org/iceb/seleccion_temas/objecionConciencia/La_Objecion_de_Conciencia.pdf

Prieto, Eugenio (2012). La objeción de conciencia, un derecho ciudadano. Bogotá, Senado de la República. En www.senado.gov.co 